\title{
Chemcomm
}

Chemical Communications 


\title{
ChemComm
}

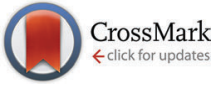

Cite this: Chem. Commun., 2016, 52,3456

Received 17th October 2015, Accepted 23rd November 2015 DOI: $10.1039 / c 5 c c 08633 g$

www.rsc.org/chemcomm

\section{Boronic acids for fluorescence imaging of carbohydrates}

\begin{abstract}
Xiaolong Sun, ${ }^{a}$ Wenlei Zhai, ${ }^{b}$ John S. Fossey ${ }^{b}$ and Tony D. James*a
"Fluorescence imaging" is a particularly exciting and rapidly developing area of research; the annual number of publications in the area has increased ten-fold over the last decade. The rapid increase of interest in fluorescence imaging will necessitate the development of an increasing number of molecular receptors and binding agents in order to meet the demand in this rapidly expanding area. Carbohydrate biomarkers are particularly important targets for fluorescence imaging given their pivotal role in numerous important biological events, including the development and progression of many diseases. Therefore, the development of new fluorescent receptors and binding agents for carbohydrates is and will be increasing in demand. This review highlights the development of fluorescence imaging agents based on boronic acids a particularly promising class of receptors given their strong and selective binding with carbohydrates in aqueous media.
\end{abstract}

\section{Introduction}

Molecular imaging is a very important tool in life sciences and engineering, and has been a particularly fast growing area of

\footnotetext{
${ }^{a}$ Department of Chemistry, University of Bath, Bath, BA2 7AY, UK.

E-mail: t.d.james@bath.ac.uk

${ }^{b}$ School of Chemistry, University of Birmingham, Edgbaston, Birmingham, West Midlands B15 2TT, UK
}

research over the past decade. Imaging techniques have been used as powerful tools to help in understanding the function and structural characteristics of tissue using intrinsic absorption and scattering via in vivo and in vitro spectroscopic and microscopy techniques. ${ }^{1,2}$ In particular, much attention has been paid to fluorescence investigations of cells and tissues since many biochemical markers can be visualised using fluorescence contrast agents, and they can also be targeted using appropriate fluorescent markers. ${ }^{3-5}$ Therefore, imaging

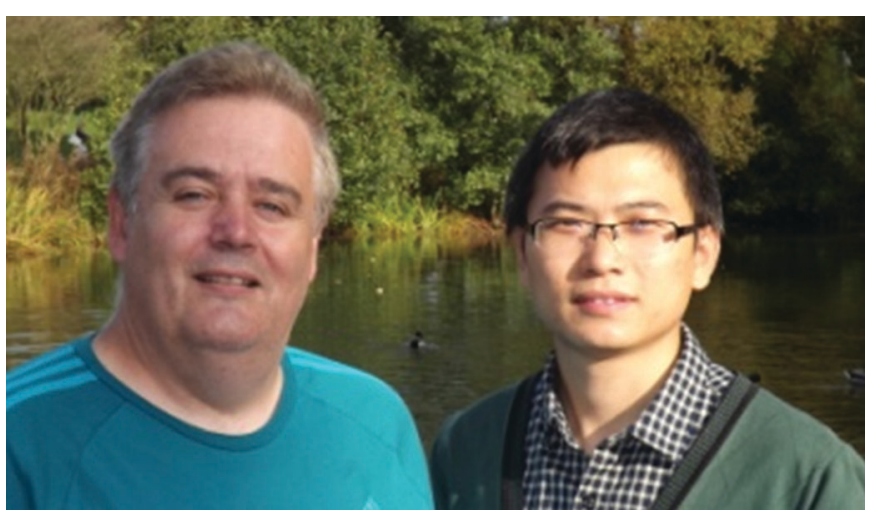

Tony James and Xiaolong Sun

Xiaolong Sun is now a postdoc working in Eric Anslyn's group, University of Texas at Austin, USA. He obtained his BSc from Shaanxi University of Science and Technology and MSc from East China University of Science and Technology (ECUST) under the supervision of Professor Xuhong Qian. He then became a PhD student with Tony D. James (Chemosensors Group) in the Department of Chemistry at the University of Bath. Research interests include organic synthesis for the preparation of small molecules, which can be used to understand and exploit biological systems, and in particular for the fluorescence detection of reactive species (oxygen and nitrogen) and carbohydrates.

Tony D. James a Professor at the University of Bath was awarded a $B S c$ in 1986 from UEA and PhD in 1991 from the University of Victoria. He worked in Japan from 1991-1995 as a PDRF with Seiji Shinkai. From 1995 to 2000 he was a Royal Society Research Fellow at University of Birmingham. In 2000 he moved to the Department of Chemistry at the University of Bath. He has been awarded the titles of visiting professor at Tsukuba, Osaka and Kyushu Universities and guest Professor at East China University of Science and Technology (ECUST), Xiamen University, Shandong Normal University, and Nanjing University; he was also awarded a Hai-Tian (Sea-Sky) Scholarship by Dalian University of Technology. Research interests include molecular recognition, self-assembly and molecular sensor development. His research has particularly concentrated on boronic acid based receptors for the sensing and detection of carbohydrates. 
techniques are important for developing and testing novel tools, reagents, and methods to visualise specific molecular processes in vivo, particularly those that are key targets in disease processes. ${ }^{6}$

Various imaging modalities, such as positron emission tomography (PET), single photon emission computed tomography (SPECT), optical fluorescence imaging, magnetic resonance imaging (MRI), computed tomography and ultrasound imaging, and recently total internal reflection fluorescence microscopy (TIRFM), have been successfully employed in biomedical imaging. ${ }^{7}$ Using these techniques for imaging, in conjunction with fluorescence, allows cellular events to be tracked providing biological information at the molecular level in living systems. ${ }^{8}$ To meet the requirement for in vivo clinical molecular imaging, the design of highly sensitive and specific molecularly targeted imaging probes is required. ${ }^{8,9}$ Imaging probes are often synthesised by combining various functional moieties (i.e. radioisotopes, fluorophores, and nanoparticles) with receptors (i.e. boronic acids and macrocyclic crown ethers). ${ }^{10,11}$ Given the successful development of singlemolecule super-resolution fluorescence imaging, precise and accurate bio-tagging and labelling can be investigated, and thus potential preclinical and biomedical detection of certain diseases at an early stage may be possible in the near future. ${ }^{12,13}$ Fluorescence molecular imaging will allow us to answer basic in vivo biological questions and more importantly it could be achieved in a high-throughput fashion. ${ }^{14}$ This review aims to capture the state-of-the-art in the emerging field of carbohydrate-led imaging; although still in its infancy, the authors of this report believe that there is an unrealised potential for carbohydrate based imaging to transform the area and offer new paradigms in biomedical research.

\section{Carbohydrates}

Carbohydrates (also known as saccharides) are vital to biological processes, and as such are important in disease diagnosis. ${ }^{15}$ For example unregulated glucose levels in the blood and associated with diabetes, which can lead to deleterious healthcare
Table 1 Structure information of the proteins ${ }^{26}$

\begin{tabular}{ll}
\hline Protein & Major associated carbohydrates \\
\hline Lectin & Terminal $\alpha$-1,3 mannose, $\alpha$-galactose, \\
& GlcNAc, $\alpha$-2,3 sialic acid, $\beta$-fucose \\
Ovalbumin (Oval) & Mannose, $N$-acetyl glucosamine, \\
& galactose \\
Bovine submaxillary mucin & Sialic acid, $N$-acetyl glucosamine, \\
(BSM) porcine stomach & $N$-acetyl galactose, fucose, galactose \\
Carcinoembryonic antigen & Sialic acid, $N$-acetyl glucosamine, \\
(CEA) & $N$-acetyl galactose, fucose, galactose, \\
& $L^{\mathrm{x}}, \mathrm{Le}^{\mathrm{a}}$, and Le antigen
\end{tabular}

implications such as kidney problems, heart disease, nerve damage (leading to amputations) and even blindness. ${ }^{16-19}$ Excess blood glucose forms non-enzymatically generated conjugates and these glycated products are what led to the damage associated with diabetes. Indeed, glycated hemoglobin (HbA1c) can be monitored to give an indication of plasma glucose. ${ }^{20}$ Such problematic glycation is more often witnessed in proteins with a long lifetime. ${ }^{21,22}$ Human serum albumin (HSA), the most prevalent blood protein, has a faster turnover rate than hemoglobin and thus comparisons between levels of HSA and hemoglobin glycation can offer meaningful insight into timedependant variations of blood sugar chemistry.

Glycated proteins offer the potential as disease markers and they are potential probes for diseases including certain types of cancers, Alzheimer's disease (AD), autoimmune diseases and atherosclerosis (Table 1). Some of the symptoms of $\mathrm{AD}$, including plaques and cell death have been linked with insulin mechanisms, because of this link in some reports the disease has been called type 3 diabetes. ${ }^{23}$ Whilst further research remains to be carried out to back-up these hypotheses, the detection of glycated proteins has the potential to offer new diagnostic regimes for clinicians in the future. It is already known that excess Advanced Glycation End products (AGE) arising from hyperglycemia are important indicators for complications related to diabetes. ${ }^{24,25}$

Cell surface carbohydrates, as a part of glycosylated proteins and lipids, have been associated with different types of cells and these surface carbohydrates present the characteristic

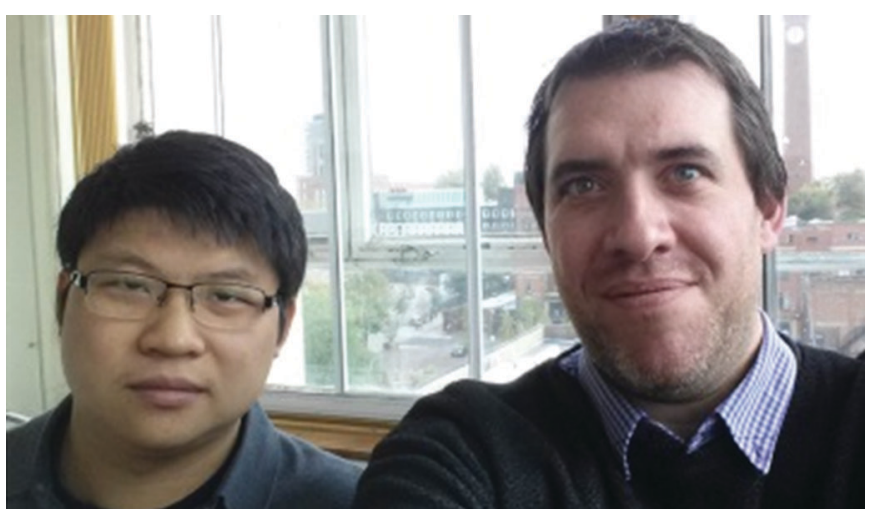

Wenlei Zhai and John Fossey

Wenlei Zhai obtained his B. Eng. degree from China Pharmaceutical University and MSc degree from East China University of Science and Technology, working with Professor Yi-Tao Long in the area of surface-enhanced Raman spectroscopy. He joined the research group of Dr J. S. Fossey three years ago where his project involves the use of click chemistry to assemble multifunctional chemosensors.

John S. Fossey is a Royal Society Industry Fellow and Senior Lecturer at the University of Birmingham, UK. He gained an MChem degree at Cardiff University of Wales in 2000, and then obtained a PhD from Queen Mary University of London in 2004, working in the group of Dr C. J. Richards. He next took up a postdoctoral position at the University of Tokyo with Professor S. Kobayashi. After three years at the University of Bath he took up his first permanent position at the University of Birmingham and was recently promoted to the position of a Senior Lecturer. He enjoys collaborative projects and research themes of molecular recognition and asymmetric catalysis, applied to disease detection and treatment, agrochemicals and novel materials. 


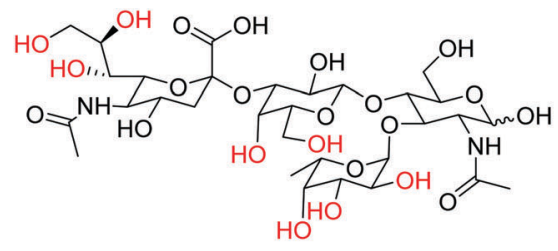

sialyl Lewis $\mathrm{X}\left(\mathrm{sLe}^{\mathrm{x}}\right)$

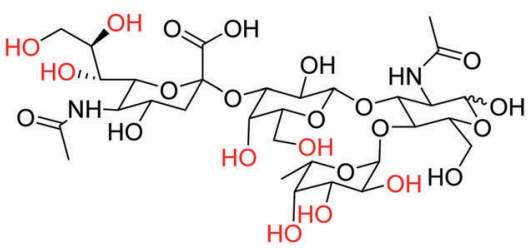

sialyl lewis A (sLe $\left.{ }^{a}\right)$

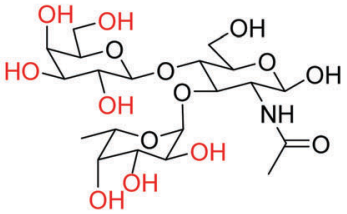

Lewis $\mathrm{X}\left(\mathrm{Le}^{\mathrm{x}}\right)$

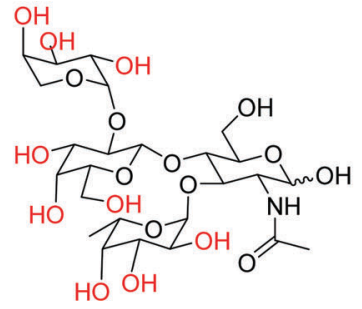

Lewis $\mathrm{Y}\left(\mathrm{Le}^{\mathrm{y}}\right)$

Fig. 1 Structures of cell-surface carbohydrates, biomarkers sialyl Lewis X (sLe $\left.{ }^{x}\right)$, sialyl lewis A (sLe $\left.{ }^{a}\right)$, Lewis $X\left(\operatorname{Le}^{x}\right)$, and Lewis $Y\left(\right.$ Le $\left.{ }^{y}\right)$. The hydroxyl groups which are most likely to bind with boronic acid groups are highlighted in red. Boronic acid receptors bind reversibly to cis-1,2- and -1,3-diols, a detailed study to ascertain which diols do bind remains to be completed.

signature of cancers' development and progression, such as sialyl Lewis $\mathrm{X}\left(\mathrm{sLe}^{\mathrm{X}}\right)$, sialyl Lewis A $\left(\mathrm{sLe}^{\mathrm{a}}\right)$, Lewis $\mathrm{X}\left(\mathrm{Le}^{\mathrm{x}}\right)$ and Lewis Y (Le ${ }^{y}$ ) (Fig. 1). ${ }^{27}$ Poly- and oligosaccharides localised on the microbial cell wall and animal cell surfaces can be targeted using sugar-specific ligands. Using these sugar-specific antibodies and lectins for controllable attachment and detachment of cells, fluorescence molecular imaging can be used for the diagnostic tracking of certain diseases or tumors.

\section{Fluorescence for imaging applications}

Since the first description of the phenomenon of fluorescence by Sir George Gabriel Stokes in $1852,{ }^{28}$ the fluorescence-related techniques have been considered as powerful tools by chemists and biologists. Fluorescence in conjunction with microscopy can be used for the detection and visualisation of biological and physiological processes and lead to a deeper understanding of disease-specific mechanisms. ${ }^{4,10}$ Fluorescent probes/molecules are widely recognized as powerful sensing and imaging tools, ${ }^{2,8,11}$ which have been successfully developed for a large number of biomolecules, including glutamate, ${ }^{29}$ acetalcholine, ${ }^{30}$ glycine, ${ }^{31}$ aspartate ${ }^{32}$ and dopamine. ${ }^{33}$ Fluorescence is particularly useful to directly interrogate cell chemistry and understand the function. ${ }^{34-36}$ The multitude of positive features, such as high sensitivity, in real-time, easy manipulation, coupled with widely available instrumentation, make fluorescence one of the most powerful transduction mechanisms to report on chemical-biological recognition events.

Fluorescent dyes can be applied to enhance image contrast in confocal fluorescence microscopy. ${ }^{37}$ The design of fluorescence probes with the ability to signal, sense and target carbohydrate substrates in living systems requires the optimisation of a number of factors, including chemoselectivity and bioorthogonality. ${ }^{38}$ In the search for synthetic receptors a bottom-up design is often required, despite the apparent challenge of designing new receptors for each analyte, there are a number of recognition motifs that offer many advantages in receptor design, such as boronic acids and their ability to sequester carbohydrates under biologically relevant conditions. ${ }^{6,39}$

Light in the near-infrared (NIR) and far-red region can propagate through several centimeters of tissue; therefore, in a practical sense the use of a NIR fluorescent signals to detect tumors and other diseases in situ and at very early stages of development is desirable. ${ }^{8}$ It should then be possible to use imaging techniques to speed up drug screening, and to use imaging as an objective endpoint for tailoring therapies towards an individual patient. ${ }^{40,41}$ Therefore, the development of "smart", and targeted fluorescent molecular probes with NIR emission is a particularly important area of interest.

\section{Boronic acid for imaging carbohydrates}

Boronic acids have been exploited extensively as chemo/biosensors in the detection of carbohydrates, anions, and reactive oxygen and nitrogen species (ROS/RNS) through electrochemical, fluorescence, and colorimetric measurements. ${ }^{6,43-47}$ Notably, over the physiological $\mathrm{pH}$ range, boronic acids are an ideal molecular receptors for 1,2- or 1,3-diols (e.g. monosaccharides) since boronic acid derivatives rapidly and reversibly interact with carbohydrates in aqueous media, and thus importantly the method does not consume the analyte. ${ }^{48-50}$ Boronic acid-based molecules and boronate-modified materials have shown great utility in sensing and imaging carbohydrates and complex glycoproteins. ${ }^{51,52}$ In terms of common cell attachment and detachment protocols, boronic acid derivatives can be utilised to bind with native polyand oligosaccharides which are present in the outer cellular wall or membrane. ${ }^{53}$ By combining boronic acid with fluorescence 
dyes or quantum dots (QDs) or other signal reporter units, researchers have developed sensing and labelling systems for the recognition of carbohydrate biomarkers. ${ }^{44}$ Since, the fluorescence quenching of probes is often hard to avoid, the development of effective boronic acid-based carbohydrate fluorescent sensors could be hampered. However, seminal research by Tang and co-workers have shown that aggregation-induced emission (AIE) systems based on tetraphenylethene (TPE) could be used to avoid quenching problems in the development of carbohydrate selective probes. ${ }^{54}$ In this feature article, we have classified boronic acid-based fluorescent probes for carbohydrate imaging into several categories: small-molecular probes, polymer-tagged probes and benzoxaborole-based probes.

\section{Small-molecule probes for imaging applications}

Over the past decade two types of small-molecule boronatebased sensors in the imaging of carbohydrates have been used: mono-boronic acid probes and bisboronic acid probes. Noticeably, bisboronic acids are more widely used due to the increased number of binding sites for interaction with carbohydrate biomarkers. ${ }^{6,55}$ The increased number of binding sites between

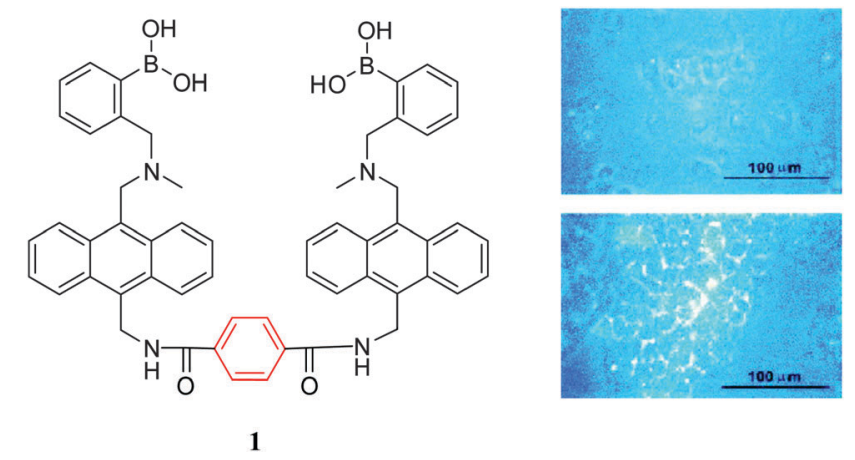

Fig. 2 Structure of compound 1 and fluorescent labelling studies of $s L e^{x}$ expressing HepG2 cells (bottom) and non-expressing COS-7 cells (top) with compound $1(5 \mu \mathrm{M})$. Reproduced with permission from (Bioorg. Med. Chem. Lett., 2002, 12, 2175). Copyright (C) 2002 Elsevier Ltd. the boronic acid receptor and carbohydrates results in a strong binding affinity and hence improved labelling or imaging of the target carbohydrate. ${ }^{49,50,56}$ For example, in 2002, Wang and co-workers ${ }^{57}$ designed and synthesised a series of fluorescent bisboronic acid probes by changing the linker between the bisboronic acid units, producing receptors for the detection of sialyl Lewis $\mathrm{X}\left(\mathrm{sLe}^{\mathrm{x}}\right)$. Among them, compound 1 with the strongest affinity for $\mathrm{sLe}^{\mathrm{x}}$ displayed specific labelling of $\mathrm{sLe}^{\mathrm{x}}$ expressing HepG2 cells, whilst non-sLe ${ }^{\mathrm{x}}$-expressing cells were not labelled in the control experiment (Fig. 2).

Wang and co-workers ${ }^{58}$ have also evaluated compound 1 and compound 2 for the selective labelling of cell-surface $\mathrm{sLe}^{\mathrm{x}}$ (HepG2 cells) over Lewis Y (Hep3B cells). The detection levels for $\operatorname{sLe}^{\mathrm{x}}$ of 0.5 to $10 \mu \mathrm{M}$ using compound $1(5 \mu \mathrm{M})$ result in the specific imaging of HepG2-expressed $\mathrm{sLe}^{\mathrm{x}}$ over Hep3Bexpressed Lewis Y (Fig. 3). However, the specific binding mode between probe $\mathbf{1}$ and $\mathrm{sLe}^{\mathrm{x}}$ which produces this selectivity was not well understood.

Based on Wang's work, a similar bisboronic acid receptor was developed by Craig. ${ }^{59}$ Three bisanthracene bisboronic acid derivatives were investigated (compounds 1, 3 and 4), with binding affinities towards D-fructose of $212 \mathrm{M}^{-1}, 266 \mathrm{M}^{-1}$ and $504 \mathrm{M}^{-1}$, respectively, and binding constants towards D-glucose of $28 \mathrm{M}^{-1}, 1 \mathrm{M}^{-1}$ and $2 \mathrm{M}^{-1}$, respectively. The compounds were used for labelling liver carcinoma cell HepG2 and normal fibroblast mammalian cell COS-7; the non-labelled cells are presented as grey images and labelled cells can be seen with a blue colour in their images. The staining results shown in Fig. 4 indicate that both compounds $\mathbf{1}$ and $\mathbf{3}$ stain the HepG2 cells and compound $\mathbf{1}$ stained COS-7 cells while compound $\mathbf{4}$ showed weak or no binding affinity for either cell line. The non-selective labelling when using compound $\mathbf{1}$ is in contrast to the earlier work which indicated specificity toward hepato-cellular carcinoma cells versus normal fibroblast cells.

In extending this work, Wang and co-workers ${ }^{60}$ have linked the carbohydrate biomarker-targeting small molecule $\mathbf{1}$ and the matrix-free MALDI mass spectrometric tag using click chemistry to produce the boronolectin-trityl reporter 5 . The new system was used to track cancer cell surface $\mathrm{sLe}^{\mathrm{x}}$ expression in freshly-frozen renal tissues. Fig. 5a shows that the system can specifically bind
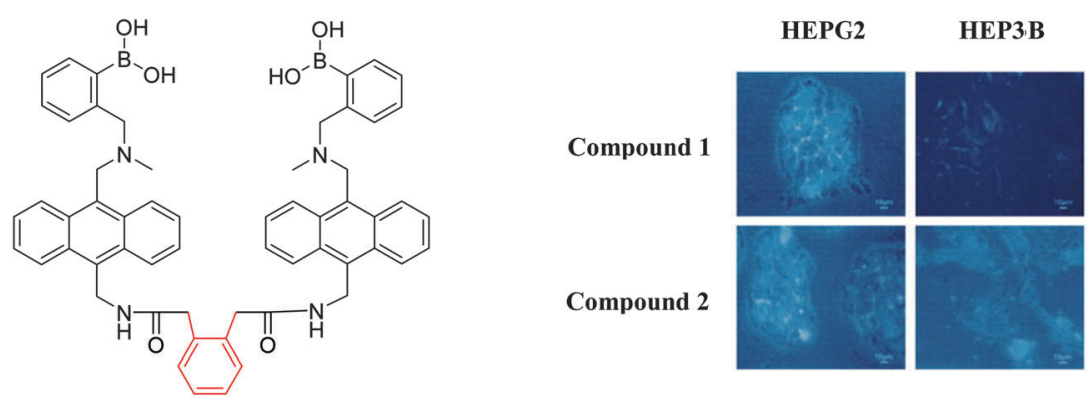

$\cos 7$

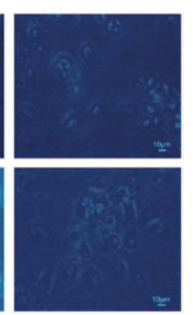

2

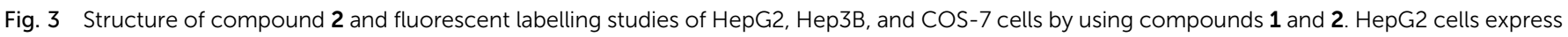

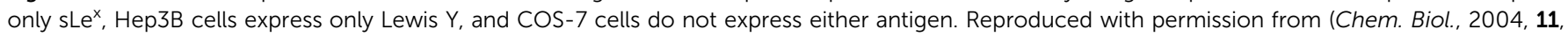
439). Copyright (C) 2004 Elsevier Ltd. 
<smiles>[R]C(=O)NCc1c2ccccc2c(CN(C)Cc2ccccc2B(O)O)c2ccccc12</smiles><smiles>[R]=Cc1cncc(C)c1</smiles>

3
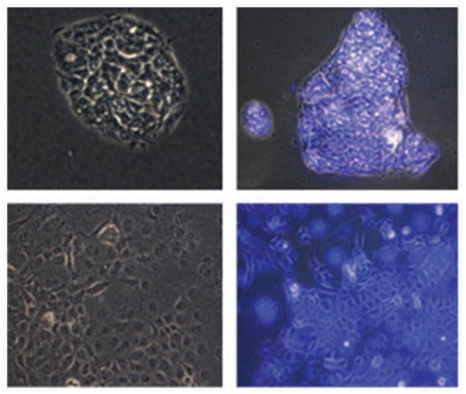

1
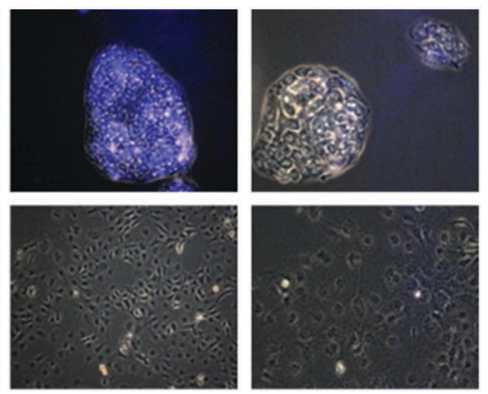

3

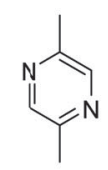

4

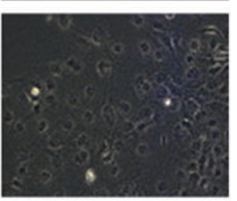

4

Fig. 4 Structures of compounds $\mathbf{3}$ and $\mathbf{4}$. Fluorescent labelling studies of a liver carcinoma cell line HepG2 and a normal fibroblast mammalian cell line COS-7 with compounds 1,3 and 4. The negative control contains buffer only. Reproduced with permission from (Bioorg. Chem., 2012, 40, 137). Copyright (C) 2012 Elsevier Ltd.

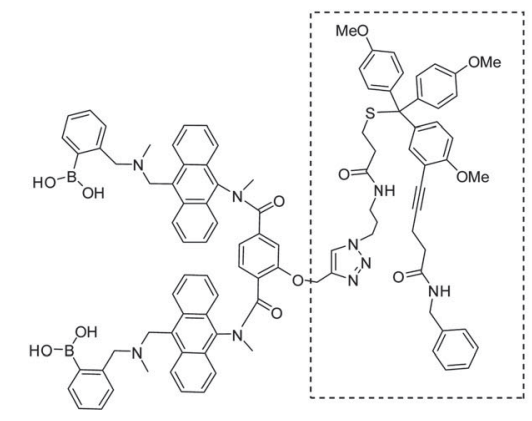

5

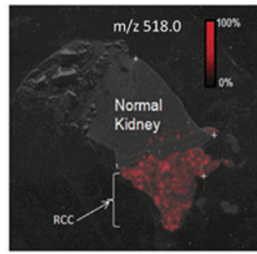

(a)

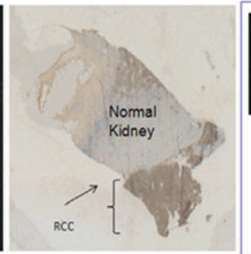

(b)

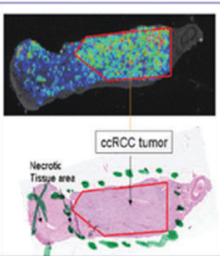

(c)

Fig. 5 (left) Structure of compound 5. (right) (a) MALDI-IMS and (b) immunostaining images of kidney tissue. Immunostaining and MALDI-IMSboronolectin signal results overlap in the tumor region, not in the normal cell areas. (c) Boronolectin staining of a Sakura/UMFix alcohol fixed renal tumor tissue. Reproduced with permission from (Chem. Commun., 2011, 47, 10338). Copyright (C) 2012 Royal Society of Chemistry.

only in the region of the tumor with $\mathrm{sLe}^{\mathrm{x}}$ expression, and also in alcohol fixed renal tumor tissue (Fig. 5b). The mass spectrometric probe was exploited in the MALDI-based imaging of cancer based on its cell surface carbohydrate.

In the recent work, Wang has reported that the over-expressed carbohydrate-based carcinoma biomarker, sialyl Lewis X, was selectively labelled in the mouse xenograft tumor via a novel boronolectin-fluorophore $6{ }^{61}$ The fluorescent agent (Fig. 6) was injected via the tail vein into a mouse with xenograft (sc) tumor for fluorescent imaging. As can be seen from Fig. 6B, after $24 \mathrm{~h}$ washing period, compound 6 could be used to target a tumor.

Above all, in Wang's systems, compound $\mathbf{1}$ showed the most promising results for binding with the important cancer-cell related biomarker $\mathrm{SLe}^{\mathrm{x}}$. The system has been further improved with the development of $\mathbf{5}$ and $\mathbf{6}$ derived from compound $\mathbf{1}$, which have been successfully used for the imaging and labelling of carbohydrate-based biomarkers in cells and tissues.

In the design of bisboronic acid systems, peptides are versatile molecules with high biocompatibility and excellent water-solubility and can be used for cancer cell detection and cancer diagnosis, including binding with over-expressed bioactive sequences such as arginine-glycine-aspartic acid and its receptors (integrins of $\alpha_{v} \beta_{3}$ and $\alpha_{v} \beta_{5}$ ). For these reasons, peptide-based linkers have been widely employed in the construction of cancer specific receptor units. Therefore, functionalisation with boronic acid derivatives at different positions along the peptide back bone 

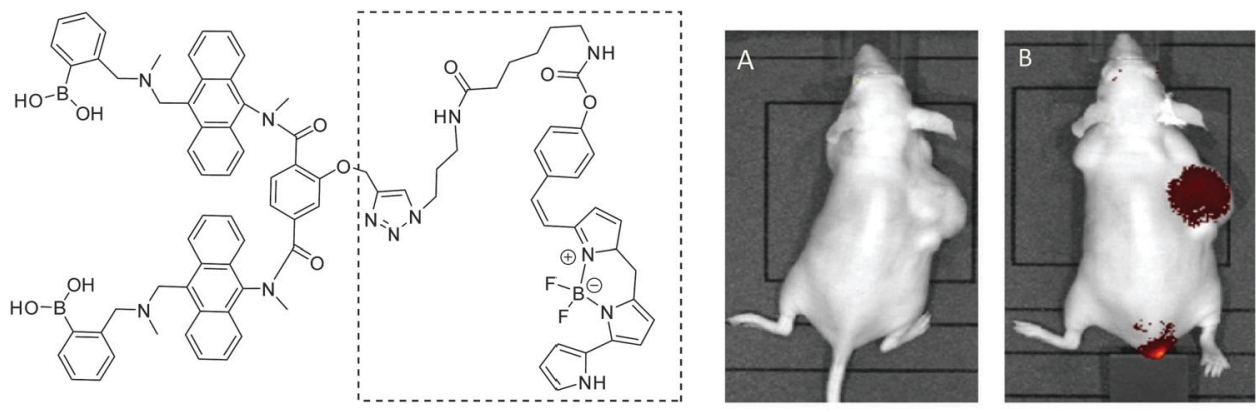

6

Fig. 6 Structure of compound 6 and its optical imaging of xenograft tumors by specific boronolectin-fluorophore 6 . (A) mouse before imaging agent injection; (B) mouse $24 \mathrm{~h}$ after tail vein injection of the contrast agent showing almost exclusive delivery to the tumor site. Reproduced with permission from (Bioorg. Med. Chem. Lett., 2013, 23, 6307). Copyright (C) 2013 Elsevier Ltd.

has resulted in new sensing and labelling probes for the in situ recognition of cell-surface glycans for the targeted imaging of cancer cells.

Lavigne and co-workers ${ }^{26}$ have prepared a bisboronic acidappended peptide library using a biased split-and-pool combinatorial approach (Fig. 7); the so-called peptide boronolectins (PBL) have been bound to beads and used for binding cancer related targets, such as oligosaccharide and glycoprotein. To investigate the ability of the peptide library to bind glycans, fluorescently labelled glycoproteins (FITC) including ovalbumin (Oval), bovine submaxillary mucin (BSM), and porcine stomach mucin (PSM) were assayed through the colour analysis output for each bead on an 8-bit scale and as revealed by the microscopy images from Fig. 8, the differential binding between different glycoproteins with peptide was observed which indicated the strong affinity between the bisboronic acid peptide receptors and the glycoproteins.

Bisboronic acid-functionalised peptide-based fluorescent sensors (BPFSs) have been prepared by Zhang and co-workers. ${ }^{62}$ They synthesised five BPFSs by incorporating anthracenephenylboronic acid within different peptide chains (Fig. 9). These sensors were then applied in situ recognition of cellsurface $\mathrm{sLe}^{\mathrm{x}}$ and integrins for fluorescent imaging of target cells (Fig. 9). In Fig. 9(B-E), fluorescence intensity of the cells increased as the incubation time between hepG2 cells and $\mathrm{BPFS}_{1}$ increases as observed by confocal laser scanning microscopy (CLSM). While, input of the CSLEX-1 antibody and the

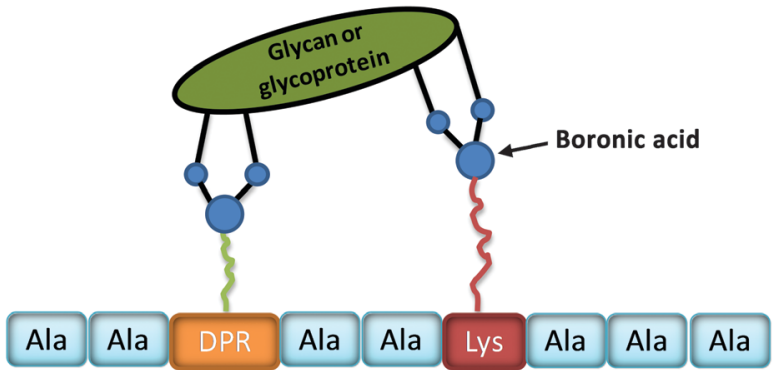

Fig. 7 Schematic representation of a phenylboronic acid substituted peptide ( $\mathrm{PBL}$, sequence chosen at random from ten amino acids) binding to a glycan or glycoprotein.
$\mathrm{BPFS}_{1}$ analogue without the boronic acid group into the cells results in a very low fluorescence intensity (Fig. $9 F_{1}$ and $G_{1}$ ). These structure-based screening processes demonstrate the specific recognition of cell-surface $\mathrm{sLe}^{\mathrm{x}}$ using phenylboronic acid groups, therefore, these sensors are promising candidates for the selective labelling of cell-surface glycans of human hepatic cancer cells.

Schepartz and co-workers ${ }^{64}$ evaluated a rhodamine-derived bisboronic acid RhoBo 7 (initially prepared as a monosaccharide sensor ${ }^{65}$ ) binding with peptides with 2-4 serine residues (each serine group presents a hydroxyl group for binding with the boronic acid receptor). Through testing different peptide sequences, it was observed that RhoBo 7 formed the highest affinity complex with peptides containing the sequence Ser-SerPro-Gly-Ser-Ser in buffer at $37^{\circ} \mathrm{C}$. Furthermore, they used Rhobo 7 to image tetraserine-containing proteins on the carbohydraterich cell surface in the cytosol using epifluorescence (Epi) and total internal reflection fluorescence microscopy (TIRFM) clearly demonstrating that tetraserine could be selectively complexed and imaged even in the presence of carbohydrates. Fig. 10 shows that only cells treated with RhoBo 7 show a significant signal (emission at $520 \mathrm{~nm}$, no fluorescence signal without RhoBo) inside the cell with maximum intensity in the nucleus and outer plasma membrane (Fig. 10B). These phenomena suggested that RhoBo is a selective small-molecule tag for tetraserine-containing proteins on and within living cells through a high affinity complex formed with bisboronic acids.

Given the advantages of bisboronic acid-tagged peptides for the targeting and sensing of cell-surface biomarkers, it may be reasonable to assume that the area will be further developed resulting in the design and development of systems for bioimaging applications. Moreover, multiple boronic acid-tagged peptides could be further developed and applied in the sensing, targeting and labelling polysaccharides, or disease-related carbohydrate biomarkers.

The next example uses a mono-boronic acid-based smallmolecular fluorescent probe; Gois ${ }^{66}$ has developed fluorescent 2-acetylbenzeneboronic acids 8 and 9 that undergo B-N promoted conjugation with lysozyme and $N$-(2-aminoethyl) folic acid (EDA-FA), resulting in conjugates that are selectively recognised and 


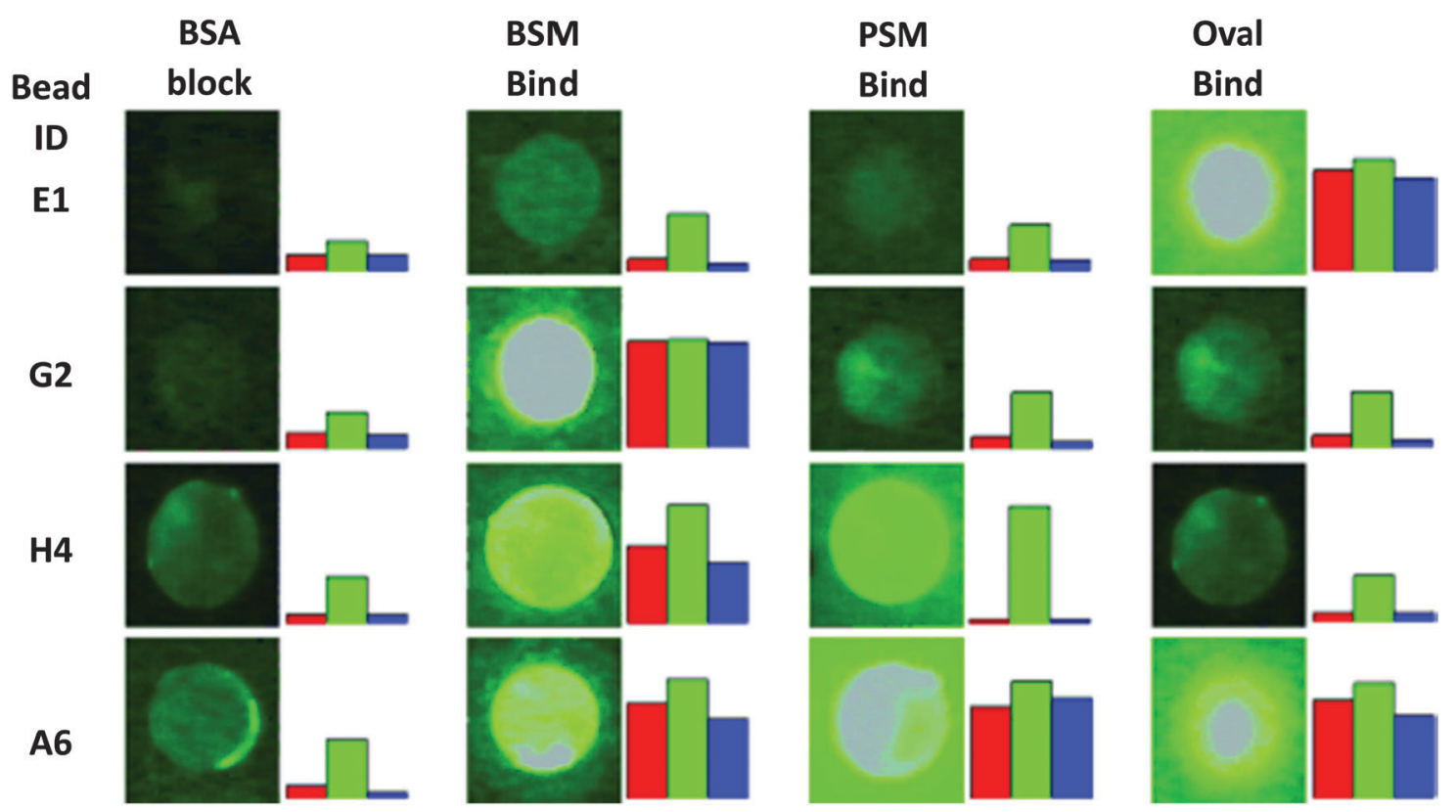

Fig. 8 Microscopy images of individual beads corresponding to FITC-labelled glycoproteins (BSA 1\% w/v; Oval, $100 \mu \mathrm{g} \mathrm{mL}{ }^{-1}$; BSM, $500 \mu \mathrm{mL} \mathrm{m}^{-1}$; PSM, $500 \mu \mathrm{g} \mathrm{mL}^{-1}$ ) and the subsequent colour (RGB) output analysis to the right of each image. The beads chosen represent selective (E1, G2), partially crossreactive $(\mathrm{H} 4)$, and completely cross-reactive (A6) library members. Reproduced with permission from (ChemBioChem, 2007, 8, 2048-2051). Copyright (C) 2007 WILEY-VCH Verlag.
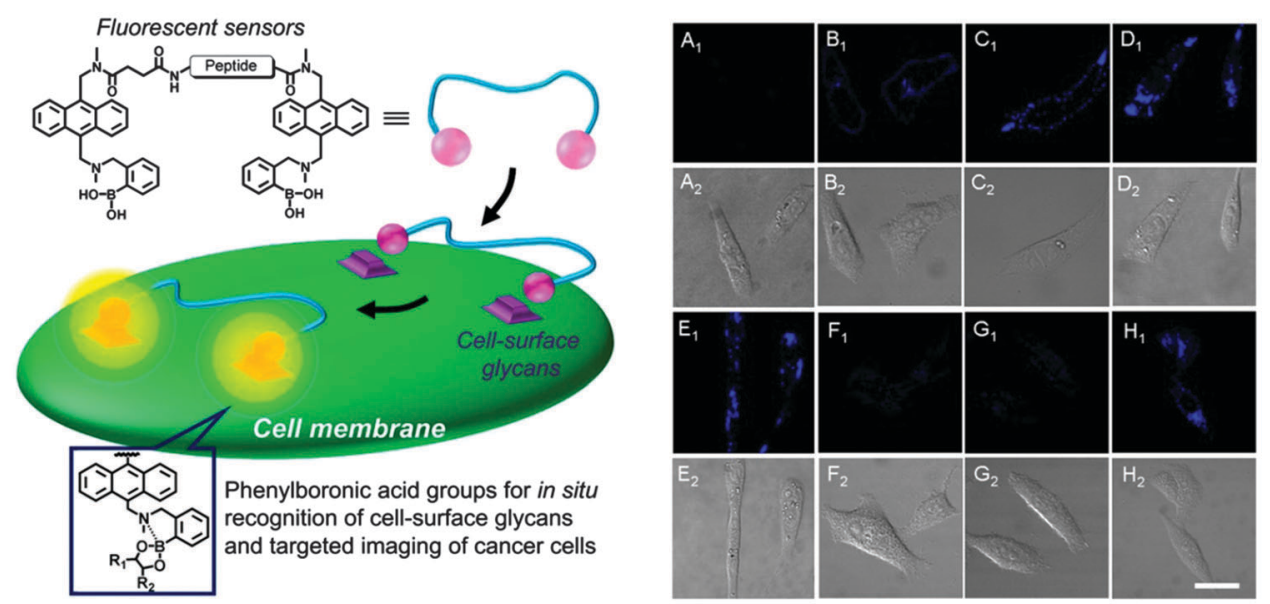

Fig. 9 (left) Schematic presentation of BPFSs for in situ cancer cell recognition and imaging. (right) (A) CLSM images ${ }^{63}$ of HepG2 cells incubated in free culture medium; (B-E) CLSM images of HepG2 cells incubated with BPFS $_{1}(20 \mu M)$ for 1 min (B), 3 min (C), 5 min (D) and 10 min (E); (F) CLSM images of HepG2 cells incubated with the antibody of CSLEX-1 for $15 \mathrm{~min}$ and then further incubated with BPFS 1 (20 $\mu$ M) for another 5 min; (G) CLSM images of HepG2 cells incubated with the BPFS 1 analogue $(20 \mu \mathrm{M})$ without phenylboronic acid groups for 10 min; (H) CLSM images of HepG2 cells incubated with $\mathrm{BPFS}_{4}(20 \mu \mathrm{M})$ with a peptide sequence of FAGDF for $5 \mathrm{~min}$. $\mathrm{A}_{1}-\mathrm{H}_{1}$ : confocal fluorescence field images; $\mathrm{A}_{2}-\mathrm{H}_{2}$ : bright field images. Reproduced with permission from (Sci. Rep., 2013, 3, 2679). Copyright (C) 2013 Nature Publishing Group.

endocytosed by NCI-H460 cancer cells only when they overexpress folic acid receptors (Fig. 11). While in the control experiment lacking the boronic acid functionality the expected constructs with the protein did not form which highlights the contribution of the boronic acid to imine stabilisation and internalisation of the conjugate.

Zhang and co-workers developed a peptide nanofibrous indicator (NFI) for naked eye-identification of cancer cells. ${ }^{67}$ The nanofibrous indicator was prepared by mixing a borono-peptide
(BP) with Alizarin Red S (compound 10). The nanofibrous selfassembly of BP/ARS produced $\beta$-sheets which can be dissociated by the addition of targets with higher binding affinities for the boronic acid than ARS (i.e. monosaccharides and cell-surface carbohydrates overexpressed on certain cancer cells). The indicator displacement assay (IDA) system was evaluated both in vivo and in vitro allowing the naked-eye evaluation of cancer cells, using boronic acid binding with HepG2 cell-surface sLe ${ }^{\mathrm{x}}$ (Fig. 12). As can be seen from Fig. 12A and C, the specific recognition between the 

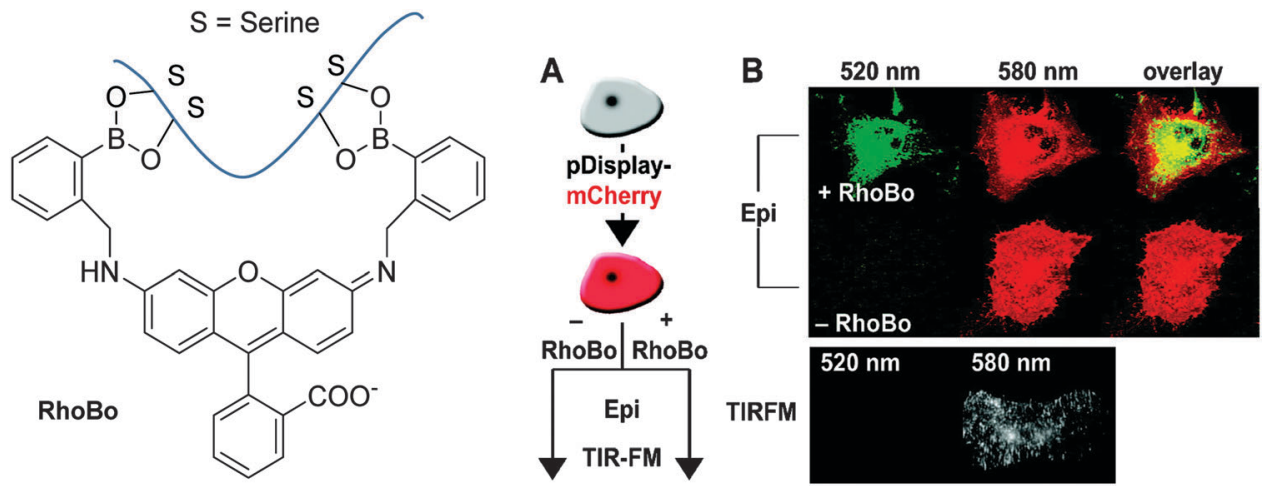

7

Fig. 10 (A) Experimental strategy to evaluate the extent of cell surface labelling by RhoBo. HeLa cells were transfected with pDisplay-mCherry (emission maximum $580 \mathrm{~nm}$ ), incubated in the presence or absence of RhoBo $(1 \mu \mathrm{M})$ (emission maximum $520 \mathrm{~nm}$ ), and (B) imaged using epifluorescent and TIRF microscopy. Reproduced with permission from (J. Am. Chem. Soc., 2009, 131, 438). Copyright (C) 2009 American Chemical Society.
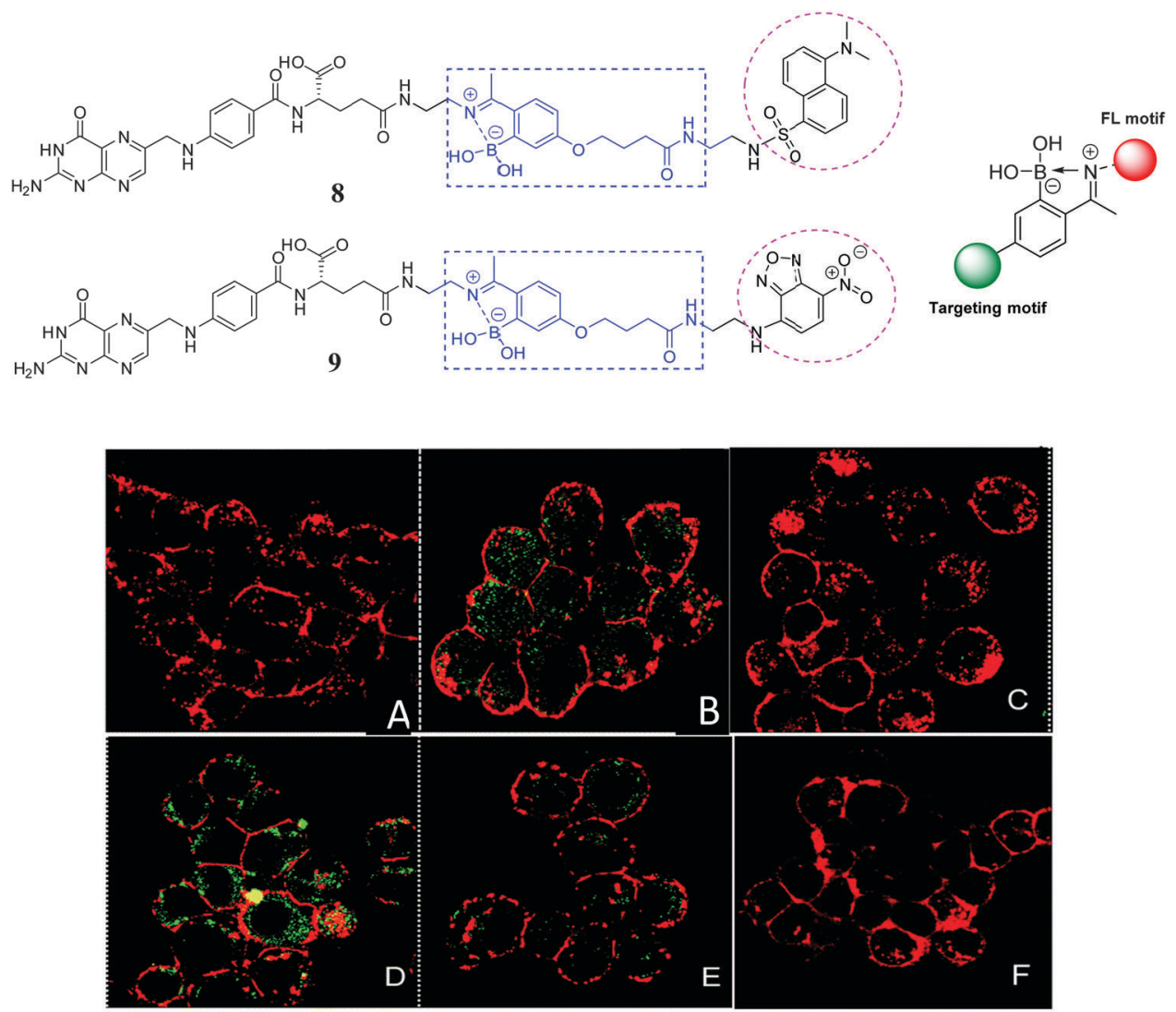

Fig. 11 Proposed structure of N-B based cancer cell targeting fluorescent conjugates $\mathbf{8}$ and $\mathbf{9}$. Optical imaging of xenograft tumor by the specific boronolectin-fluorophore. (A) $\mathrm{HEK}$ and (B) NCl-H460 cells were incubated with compound 8; (C) NCl-H460 and (D) NCl-H460 without and (E) with pretreatment with EDA-FA were incubated with compounds 9; (F) NCl-H460 treated with no boron compound. Images show an overlay of the emission of compounds in the $460-580 \mathrm{~nm}$ regions upon excitation at $458 \mathrm{~nm}$ (green), and the emission of the membrane marker in the 650-700 $\mathrm{nm}$ regions upon excitation at $514 \mathrm{~nm}$ (red). Reproduced with permission from (Chem. Commun., 2014, 50, 5261). Copyright (C) 2014 Royal Society of Chemistry.

boronic acid NFI and cell-surface $\operatorname{sLe}^{\mathrm{x}}$ resulted in a weak fluorescence from ARS released from the BP/ARS complex. While HepG2 and COS-7 cells showed a strong red fluorescence (Fig. 12B and D), indicating that the BP and ARS can be internalised and combine with each other to form a fluorescent BP/ARS complex.

\section{Polymer-tagged boronic acid probes for imaging application}

A significant enhancement in the binding of saccharide containing biomolecules, and hence the performance of a sensor system, can be achieved by incorporation of boronic acid units 

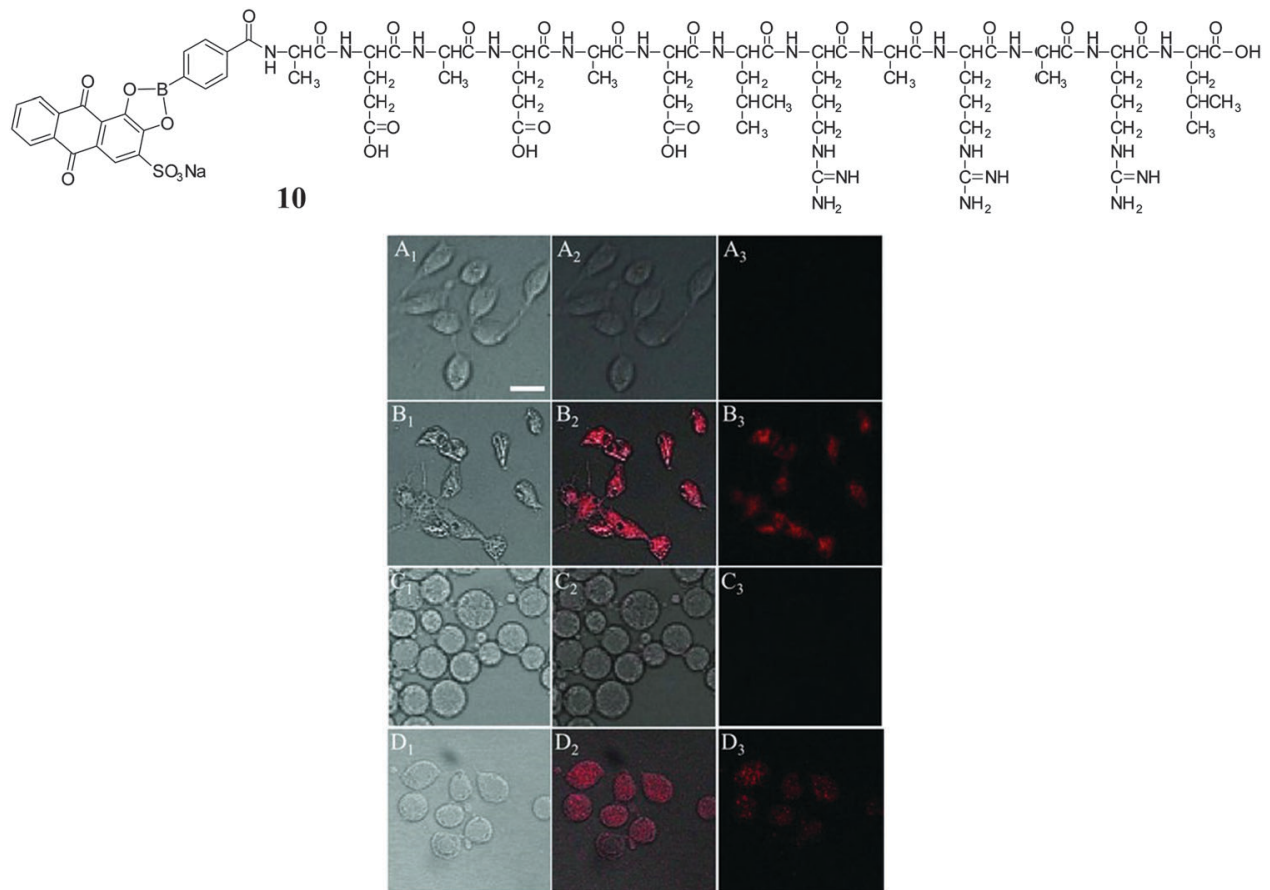

Fig. 12 Confocal laser scanning images of HepG2/COS-7 cells co-incubated with the NFI and with BP followed by the addition of ARS. ( $\left.A_{1-3}\right)$ HepG2 cells co-incubated with the NFI; $\left(B_{1-3}\right)$ HepG2 cells co-incubated with BP and then ARS added; $\left(C_{1-3}\right)$ COS-7 cells co-incubated with the NFI; $\left(D_{1-3}\right)$ COS-7 cells co-incubated with BP and then ARS added. Reproduced with permission from (Small, 2013, 9, 920). Copyright (C) 2013 WILEY-VCH Verlag.

into a polymer matrix. ${ }^{6,68,69}$ Boronic acid-containing polymers have been found to be valuable in a variety of biomedical applications, including the treatment of $\mathrm{HIV},{ }^{70,71}$ obesity ${ }^{72,73}$ diabetes, ${ }^{6}$ and cancer. ${ }^{74,75}$ Inclusion of the molecular sensor in the polymer can help in the development of superior analytical devices for carbohydrate imaging, since the polymer imparts many advantages such as improved robustness, sensitivity, handling, and biocompatibility. These properties are vital for the development of noninvasive biomolecular imaging tools. ${ }^{76,77}$

In the design of a novel stimuli-responsive controlled-release system, Lin and co-workers ${ }^{78}$ visualised intracellular delivery of both insulin and cAMP (cyclic adenosine monophosphate) by using a 8-Fluo-cAMP-loaded BA-MSN particles (boronic acidmesoporous silica nanoparticle) that can internalise within live RIN-5F cells (Scheme 1). The importance of this work is to overcome the difficulty of control of intracellular cAMP delivery by a drug carrier. By the introduction of carbohydrates (Fig. 13b and c), green fluorescence in fluorescence confocal micrographs was clearly observed for both Fluo-cAMP-loaded BA-MSN particles and the free Fluo-cAMP molecules released from the MSN intracellularly by interaction of the boronic acid with glucose in live mammalian cells (Fig. 13).

To make fluorescent glucose probes developed from QDs more practical for intracellular imaging, modified CdTe/ZnTe/ ZnS core/shell/shell (CSS) QDs bearing phenylboronic acid (PBA) were prepared by Zhou et al. through attaching PBAfunctionalised groups to the QD surface (Fig. 14a). ${ }^{79}$ Glucosemediated assembly of PBA-QDs was monitored by dynamic light scattering (DLS), TEM images were used to characterize the changes of QD properties before and after the addition of glucose. The unique glucose-mediated assembly of PBA-QDs could be used to modulate the photoluminescence (PL) properties of the QDs and results in a selective ratiometric response towards glucose (Fig. 14a). The ability of the PBA-QDs to enter cells and
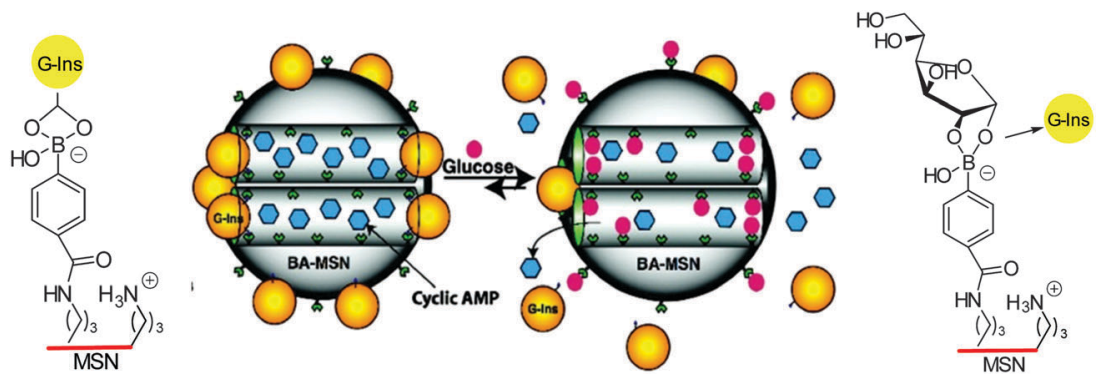

Scheme 1 Schematic representation of the glucose-responsive MSN-based delivery system for controlled release of bioactive gluconic acid-modified insulin (G-Ins) and CAMP. Reproduced with permission from (J. Am. Chem. Soc., 2009, 131, 8398). Copyright a 2009 American Chemical Society. 

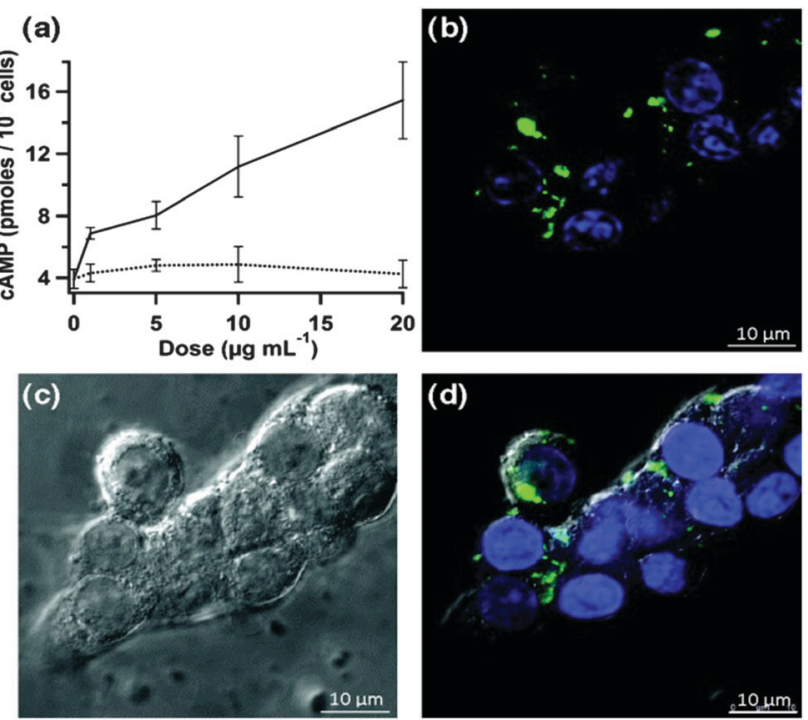

Fig. 13 (a) Intracellular CAMP concentration of rat pancreatic RIN-5F cells treated with the CAMP-loaded BA-MSN (solid line) and free-solution CAMP (dashed line), measured after $6 \mathrm{~h}$ of introduction; (b) fluorescence confocal micrograph of RIN-5F cells incubated with $20 \mu \mathrm{g} \mathrm{mL}^{-1}$ Fluo-cAMP-loaded BA-MSN (green) for $6 \mathrm{~h}$. Cell nuclei were stained with DAPI (blue). (c) Corresponding differential interference contrast (DIC) micrographs. (d) Fluorescence confocal and DIC merged image. Reproduced with permission from (J. Am. Chem. Soc., 2009, 131, 8398). Copyright (C) 2009 American Chemical Society.

detect intracellular glucose levels in mouse melanoma B16F10 cells (grown in sugar-free Dulbecco modified Eagle medium) was then tested. When B16F10 cells were treated with PBA-QDs, a cross-sectional Z scan confirmed the entry of the QDs into the cells (Fig. 14b left). A continuous irradiation assay confirmed the photostability of the QDs in the cells. Subsequently the cells were fed with different amounts of glucose, and the emission maximum of PBA-QDs shifted from $590.2 \mathrm{~nm}$ to $596.7 \mathrm{~nm}$ and $609.8 \mathrm{~nm}$ corresponding to glucose at concentrations of about 4.0 and $15.9 \mathrm{mM}$, respectively (Fig. 14b). Thus, the unique glucose-mediated assembly of the PBA-modified QDs could be applied for a selective ratiometric response to glucose through modulating the PL properties of QDs in living cells.

It is particularly challenging to design fluorescence-based systems for continuous glucose monitoring (CGM) in vivo. To overcome some of the problems, an injectable hydrogel fashioned into microbeads, which incorporates an established glucose selective fluorescent sensor (GF-hydrogel) was developed by Takeuchi and co-workers (Fig. 15 left). ${ }^{80}$ The glucose-responsive bead (GF) system was highly-sensitive, bio-stable, long-lasting, and injectable for in vivo continuous glucose detection (Fig. 15 right). Significantly, the fluorescence intensity of the injected GF-beads was transdermally detectable and visible through the ear skin of mice without any abnormalities for over 30 days (Fig. 15A and B). They also experimentally verified the correlation between the fluorescence intensity of the implanted GF-beads and the in vivo blood glucose concentrations (370-130 $\mathrm{mg} \mathrm{dL}^{-1}$, modulated by insulin) by nine intravenous glucose infusions and found that the fluorescence intensity of the microbeads could be used to accurately monitor the blood glucose concentrations (Fig. 15C-G).

In order to address two limitations: (i) that continuous glucose monitoring may not be required over the whole lifetime of the subject and (ii) that the microbeads slowly disperse, they have moved to a more robust and easily removable fiber sensor system. ${ }^{81}$ The fiber material consists of polyethylene glycol (PEG)-bonded polyacrylamine (PAM) hydrogels and incorporates the same sensor unit. ${ }^{82}$ In their smart structure design, polyethylene glycol (PEG)-bonded polyacrylamide (PAM) hydrogel fibers (with better performance than PAM hydrogel fibers) were employed since they can reduce inflammation and continuously respond to blood glucose changes for up to 140 days. The fiber system can be used for long-term in vivo glucose monitoring, and fibers still showed a very strong fluorescence signal through ear skin even one month after implantation (Fig. 16). These fibers can also be implanted and removed quickly and simply (Fig. 17), which has the additional advantage that unknown long-term side effects are not given the chance to manifest.
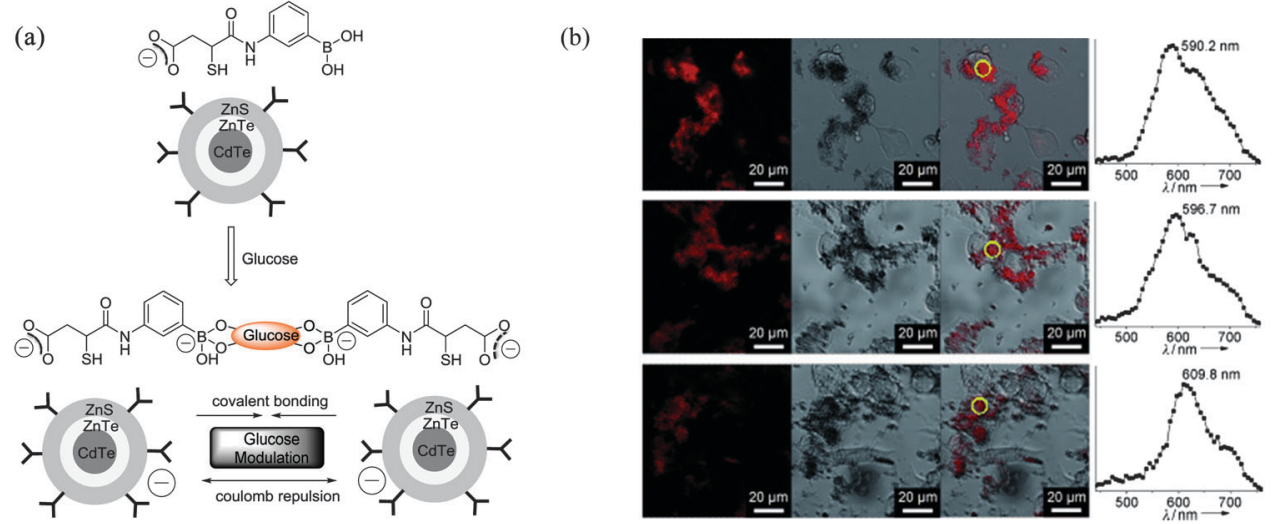

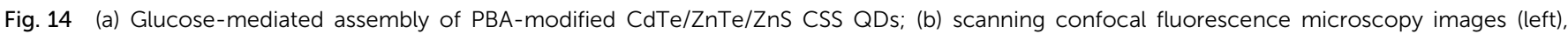

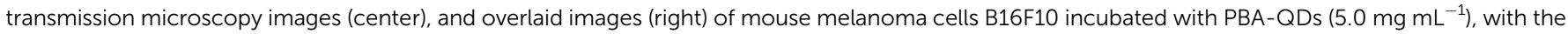

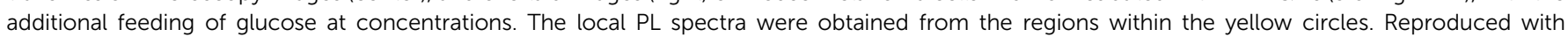
permission from (Angew. Chem., Int. Ed., 2010, 122, 6704). Copyright (C) 2010 WILEY-VCH Verlag. 


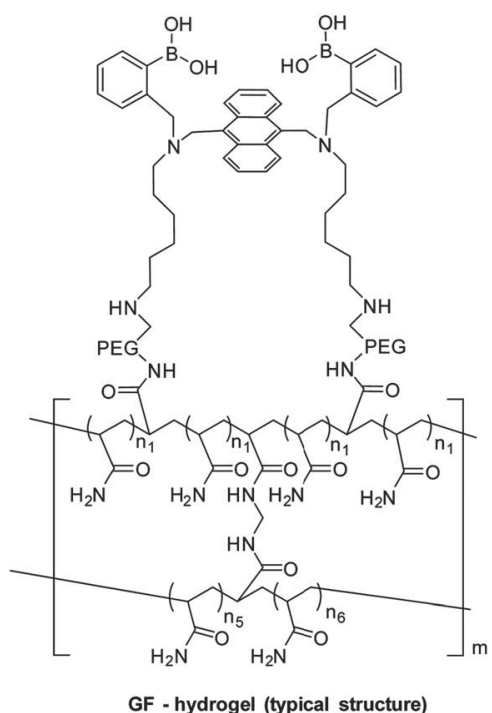

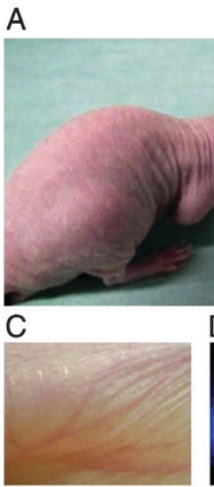

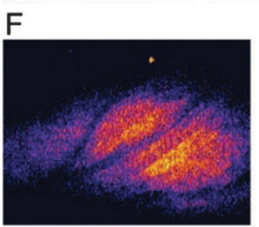

$\mathrm{B}$
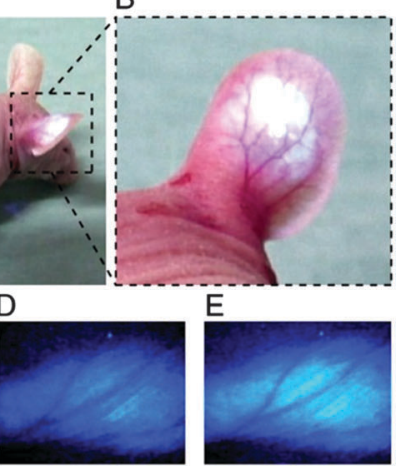

G

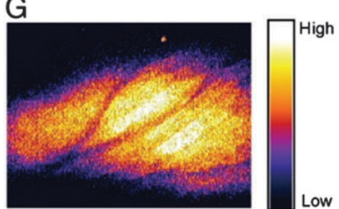

Fig. 15 (left) Typical structure of GF-polyacrylamide hydrogels; (right) in vivo CGM in a mouse using injected GF-beads. (A and B) Glucose responsive fluorescence beads under the dermis of a mouse ear. (C) Enlarged view of the implantation site in the mouse ear. (D and E) Fluorescent images for glucose concentration within the euglycemic and hyperglycemic ranges, respectively. (F and G) Pseudocoloured images of D and E. Reproduced with permission from (Proc. Natl. Acad. Sci. U. S. A., 2010, 107, 17894) Copyright (C) by the National Academy of Sciences.

AM

PAM

Day 0
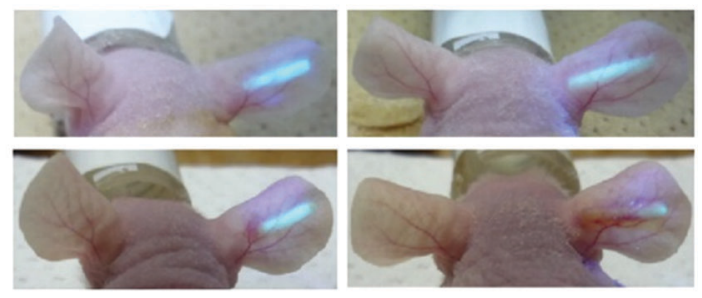

Fig. 16 Inflammation induced by the implanted fibers and transdermal transmission over a long period. The comparison of fluorescence intensity of the PAM hydrogel fibers with and without PEG through the ear skin for one month. Reproduced with permission from (Proc. Natl. Acad. Sci. U. S. A., 2011, 108, 13399) Copyright (C) by the National Academy of Sciences.
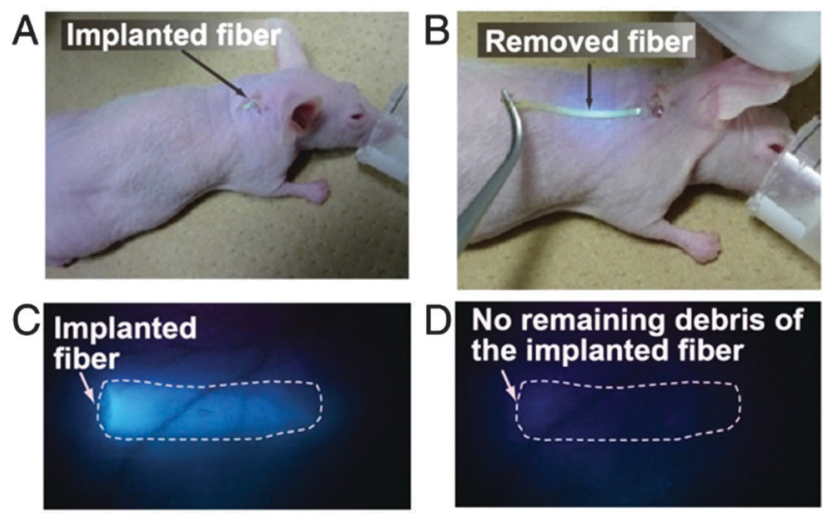

Fig. 17 The implanted fiber can be easily removed from the implantation site after use. (A) Fiber implanted into the mouse ear. (B) The implanted fiber was easily removed from the ear. (C) Fluorescence image of the mouse ear before removing. (D) Fluorescent image after fiber removal. Reproduced with permission from (Proc. Natl. Acad. Sci. U. S. A., 2011, 108, 13399). Copyright (C) by the National Academy of Sciences.
In addition, Elsen has demonstrated that glycated proteins can be visualised and identified in a variety of complex biological samples, including human serum, Manduca sexta hemolymph and mouse brain cortex homogenates, using fluorescent boronic acids in Flu-PAGE and Flu-BLOT. ${ }^{82}$

\section{Benzoxaborole-based probes for imaging applications}

Dennis Hall pioneered the use of the benzoxaborole 11 (orthohydroxymethyl phenylboronic acid) receptor which has been shown to be a superior receptor unit to the well-established dialkylamino boronic acid (Wulff type, compounds 1-9) analogues. ${ }^{83}$ The benzoxaborole 11 unit binds strongly with 4,6-diols and as such can be used to complex strongly with cell-surface glycoconjugates (Scheme 2). ${ }^{84}$

Inefficient cellular delivery limits the application of macromolecular drugs. ${ }^{85,86}$ Therefore, through the targeting of therapeutic agents to the glycocalyx, it is anticipated that this would enhance the cellular delivery of the drug. In order to evaluate this concept, Raines has conjugated benzoxaborole moieties with bovine pancreatic ribonuclease (RNase A) and used the enhanced affinity towards: D-fructose, D-glucose and $N$-acetylneuraminic (Neu5Ac) to aid intracellular targeting of the conjugate. ${ }^{87}$ In the design, 5-amino2-hydroxymethylphenylboronic acid was linked via an amide bond to the protein carboxyl groups using a carbodiimide coupling agent (Fig. 18a). A fluorophore-labelled protein and flow cytometry were used to quantify cellular internalisation. Chinese hamster ovary cells (Lec-2) were employed since they have lower levels of sialic acid in their glycocalyx than their progenitor line (Pro-5). This experiment was designed to determine whether the conjugated benzoxaborole would elicit selectivity for 


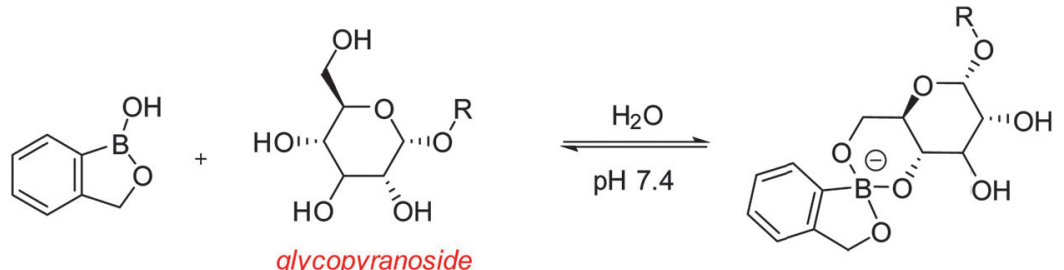

11

Scheme 2 Reversible covalent bonding between benzoborole and glycopyranoside.

(a)

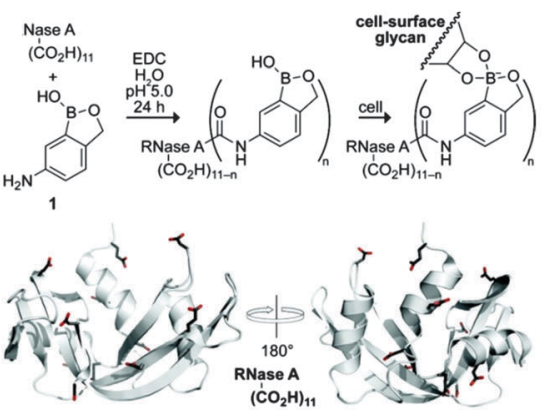

(b)

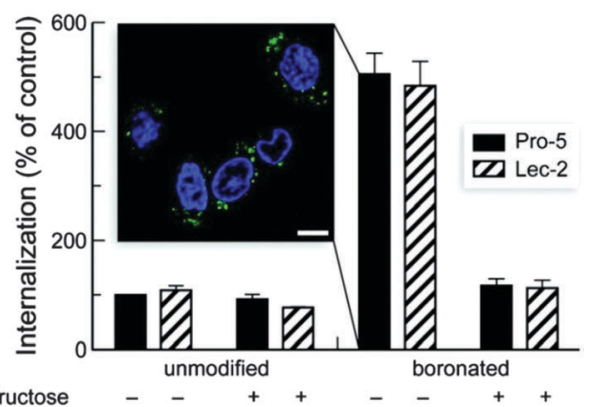

Fig. 18 (a) Boronation of RNase A and its proposed mechanism for expediting cellular delivery. The location of each carboxyl group of RNase A is depicted in the ribbon diagram. (b) Internalisation of unmodified and boronated RNase A into Pro-5 and Lec-2 cells in the absence or presence of fructose. Flow cytometry data were normalized to the internalisation of unmodified RNase A into Pro-5 cells. Error bars represent SDs. Inset: Confocal microscopy image of live Pro-5 cells incubated for $4 \mathrm{~h}$ with boronated RNase A that had been labelled covalently with a green fluorophore. Nuclei were stained blue with Hoechst 33322. Reproduced with permission from (J. Am. Chem. Soc., 2012, 134, 3631). Copyright (C) 2012 American Chemical Society.
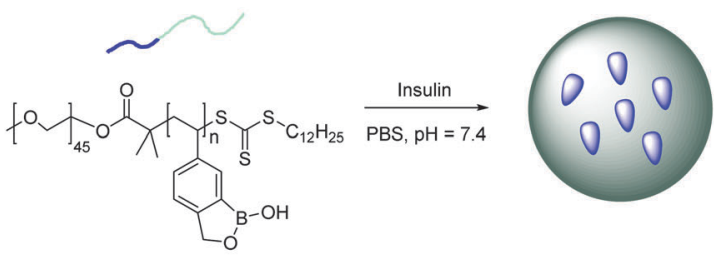

$\underset{\text { glucose/fructose }}{\longrightarrow}$

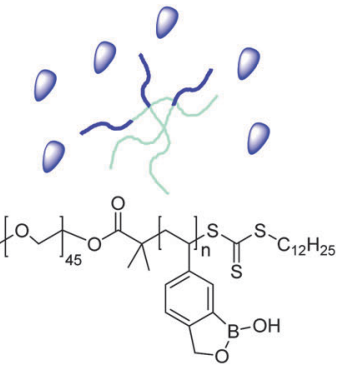

Scheme 3 Self-assembly of PEG-b-PBOx and its disassembly in the presence of monosaccharides.

cells with higher quantities of cell-surface sialic acid since sialic acid is of high abundance in the glycocalyx. It was found that boronation of RNase A increased its cellular uptake by 4 to 5 -fold (Fig. 18b). Thus, it was shown that the boronated protein has enhanced affinity for in vitro oligosaccharides and also facilitates cellular uptake of the protein and enhances protein delivery to the cytosol. It was concluded that such benzoxaborole have many attractive attributes and could be used as ideal mediators in drug delivery.

Kim developed a benzoxaborole-containing styrenic monomer which can be polymerised by the reversible addition-fragmentation and chain transfer method. The Poly(styreneboroxole) (PBOx) formed was combined with a hydrophilic block of poly(ethylene glycol) (PEG). Polymersomes formed from the block polymer disassembled in the presence of monosaccharides to release insulin at neutral pH (Scheme 3) ${ }^{88}$ Fluorescein isothiocyanate (FITC)-labelled human insulin (F-insulin) was encapsulated within polymersomes, in order to demonstrate their use as sugar-responsive containers. The strong green fluorescence of the polymersomes was observed using laser confocal fluorescence microscopy (LCFM, Fig. 19). Subsequently, under physiologically relevant $\mathrm{pH}$ conditions, the FITC labelled insulin was released from the polymersomes

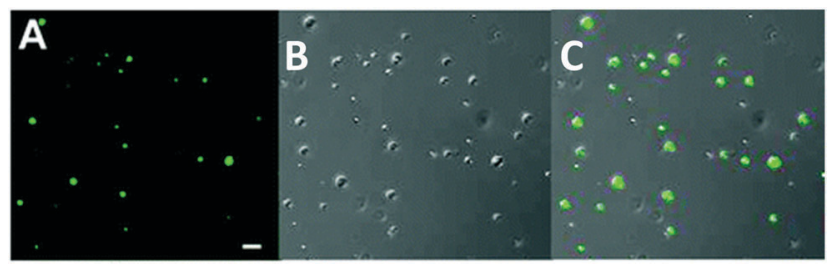

Fig. 19 LCFM images of polymersomes of PEG- $b$-PBOx encapsulating FITC-labelled human insulin: (A) dark-field, (B) bright-field; (C) merged. Scale bar: $5 \mu \mathrm{m}$. Reproduced with permission from (J. Am. Chem. Soc., 2012, 134, 4030). Copyright (C) 2012 American Chemical Society. 
in response to added monosaccharides that bind strongly with the benzoxaborole moieties.

\section{Conclusions}

Cellular imaging using fluorescent reporter systems for tagging cellular and subcellular processes in vivo have been extensively developed over the past decade but many important challenges remain, such as chemoselectivity, bioorthogonality and continuous in vivo monitoring. It is clear that if more research can be encouraged in this area then substantial developments will be possible and these will impact the way we currently do biological research, drug discovery, and clinical practice. Especially given the rapid development of super-resolution fluorescence microscopy (2014 Nobel Prize in chemistry), which will bolster the development of fluorescence molecular imaging for diagnostics and also the monitoring disease progression and recovery at the molecular level. ${ }^{89}$ Carbohydrates are particularly important targets given their pivotal role in numerous important biological events, including the development and progression of many diseases. Boronic acids (BA) are a class of receptors very well suited to the binding of carbohydrates, since even the simplest BA receptors have high affinity for carbohydrates under biologically relevant conditions (in water). Putting things into perspective if boronic acid based imaging agents could aid in the development of early stage diagnostics or aid the development of treatment for just one disease such Alzheimer's disease (AD). Then, the overall economic impact would be immense, since the current economic burden of dementia per year on the UK is $£ 26.3$ billion..$^{90}$ Obviously, the answer to this problem is not going to be easy but given the rapid growth of interest in selective "fluorescence imaging" and potential of boronic acid based receptors discussed in this review we hope that solutions to these problems will be provided in the relatively near future.

\section{Acknowledgements}

XS, WZ, JSF and TDJ would like to thank The Catalysis and Sensing for our Environment (CASE) for networking opportunities. ${ }^{91}$ XS thanks the China Scholarship Council (CSC) and University of Bath for a Full Fees Scholarship. TDJ thanks the University of Bath for support. China Scholarship Council (CSC) and the University of Birmingham are also thanked for providing studentship support (WZ). JSF thanks the University of Birmingham for support, the Royal Society for an Industrial Fellowship and the EPSRC for funding (EP/J003220/1). JSF and TDJ are grateful for past collaborative support (DT/F00267X/1).

\section{References}

1 A. Signore, S. J. Mather, G. Piaggio, G. Malviya and R. A. Dierckx, Chem. Rev., 2010, 110, 3112-3145.

2 A. S. Stender, K. Marchuk, C. Liu, S. Sander, M. W. Meyer, E. A. Smith, B. Neupane, G. Wang, J. Li, J.-X. Cheng, B. Huang and N. Fang, Chem. Rev., 2013, 113, 2469-2527.

3 Y. Zhou, J. F. Zhang and J. Yoon, Chem. Rev., 2014, 114, 5511-5571.
4 E. L. Que, D. W. Domaille and C. J. Chang, Chem. Rev., 2008, 108, 1517-1549.

5 X.-P. He, Y. Zang, T. D. James, J. Li and G.-R. Chen, Chem. Soc. Rev., 2015, 44, 4239-4248.

6 X. Sun and T. D. James, Chem. Rev., 2015, 115, 8001-8037.

7 S. Lee, J. Xie and X. Chen, Chem. Rev., 2010, 110, 3087-3111.

8 H. Kobayashi, M. Ogawa, R. Alford, P. L. Choyke and Y. Urano, Chem. Rev., 2010, 110, 2620-2640.

9 X. Li, X. Gao, W. Shi and H. Ma, Chem. Rev., 2014, 114, 590-659.

10 M. Vendrell, D. Zhai, J. C. Er and Y.-T. Chang, Chem. Rev., 2012, 112, 4391-4420.

11 A. P. de Silva, H. Q. N. Gunaratne, T. Gunnlaugsson, A. J. M. Huxley, C. P. McCoy, J. T. Rademacher and T. E. Rice, Chem. Rev., 1997, 97, 1515-1566.

12 M. Bates, B. Huang, G. T. Dempsey and X. Zhuang, Science, 2007, 317, 1749-1753.

13 R. Henriques, C. Griffiths, E. Hesper Rego and M. M. Mhlanga, Biopolymers, 2011, 95, 322-331.

14 Y. Aoyama, Y. Tanaka, H. Toi and H. Ogoshi, J. Am. Chem. Soc., 1988, 110, 634-635.

15 H. E. Murrey and L. C. Hsieh-Wilson, Chem. Rev., 2008, 108, 1708-1731.

16 C. The Emerging Risk Factors, Lancet, 2010, 375, 2215-2222.

17 P. Luppi, V. Cifarelli and J. Wahren, Pediatr. Diabetes, 2011, 12, 276-292.

18 N. J. Ammary-Risch, M. Aguilar, L. S. Goodman and L. Quiroz, Fam. Community Health, 2012, 35, 103-110.

19 M. Rosati, M. Lisanti, A. Baluganti, L. Andreani, L. Rizzo and A. Piaggesi, Musculoskelet. Surg., 2012, 96, 191-197.

20 E. Selvin, M. W. Steffes, H. Zhu, K. Matsushita, L. Wagenknecht, J. Pankow, J. Coresh and F. L. Brancati, N. Engl. J. Med., 2010, 362, 800-811.

21 M. B. Davidson, D. L. Schriger, A. L. Peters and B. Lorber, JAMA, 1999, 281, 1203-1210.

22 D. McCane, R. L. Hanson, M.-A. Charles, L. T. Jacobsson, D. D. Pettitt, P. H. Bennett and W. C. Knowler, BMJ, 1994, 308, 1323-1328.

23 M. Suzanne and J. R. Wands, J. Diabetes Sci. Technol., 2008, 2, 1101-1113.

24 M. P. Pereira Morais, J. D. Mackay, S. K. Bhamra, J. G. Buchanan, T. D. James, J. S. Fossey and J. M. van den Elsen, Proteomics, 2010, 10, $48-58$.

25 M. P. P. Morais, J. S. Fossey, T. D. James and J. M. van den Elsen, Protein Electrophoresis, Springer, 2012, pp. 93-109.

26 Y. Zou, D. L. Broughton, K. L. Bicker, P. R. Thompson and J. J. Lavigne, ChemBioChem, 2007, 8, 2048-2051.

27 C. F. Dai, A. Sagwal, Y. F. Cheng, H. J. Peng, W. X. Chen and B. H. Wang, Pure Appl. Chem., 2012, 84, 2479-2498.

28 S. G. G. Stokes, Rep. Br. Ass., 1852, 15-16.

29 M. A. Brun, K.-T. Tan, R. Griss, A. Kielkowska, L. Reymond and K. Johnsson, J. Am. Chem. Soc., 2012, 134, 7676-7678.

30 D.-S. Guo, V. D. Uzunova, X. Su, Y. Liu and W. M. Nau, Chem. Sci., 2011, 2, 1722-1734.

31 E. K. Feuster and T. E. Glass, J. Am. Chem. Soc., 2003, 125, 16174-16175.

32 J. M. West, H. Tsuruta and E. R. Kantrowitz, J. Biol. Chem., 2004, 279, 945-951.

33 K. E. Secor and T. E. Glass, Org. Lett., 2004, 6, 3727-3730.

34 J. S. Paige, T. Nguyen-Duc, W. Song and S. R. Jaffrey, Science, 2012, 335, 1194.

35 S. H. Shim, C. Xia, G. Zhong, H. P. Babcock, J. C. Vaughan, B. Huang, X. Wang, C. Xu, G. Q. Bi and X. Zhuang, Proc. Natl. Acad. Sci. U. S. A., 2012, 109, 13978-13983.

36 X.-P. He, Q. Deng, L. Cai, C.-Z. Wang, Y. Zang, J. Li, G.-R. Chen and H. Tian, ACS Appl. Mater. Interfaces, 2014, 6, 5379-5382.

37 E. M. Sevick-Muraca, J. P. Houston and M. Gurfinkel, Curr. Opin. Chem. Biol., 2002, 6, 642-650.

38 J. Chan, S. C. Dodani and C. J. Chang, Nat. Chem., 2012, 4, 973-984.

39 S. D. Bull, M. G. Davidson, J. M. H. Van den Elsen, J. S. Fossey, A. T. A. Jenkins, Y.-B. Jiang, Y. Kubo, F. Marken, K. Sakurai, J. Zhao and T. D. James, Acc. Chem. Res., 2013, 46, 312-326.

40 V. Ntziachristos, C. Bremer and R. Weissleder, Eur. J. Radiol., 2003, 13, 195-208.

41 V. Ntziachristos, J. Ripoll and R. Weissleder, Opt. Lett., 2002, 27, 333-335. 
42 "smart" here means the proper design of a good sensing system with not only high sensitivity but also chemoselectivity and bioorthogonality while also the system can be easily prepared and work very well in a specific environment.

43 A. R. Lippert, G. C. Van de Bittner and C. J. Chang, Acc. Chem. Res., 2011, 44, 793-804.

44 W. Zhai, X. Sun, T. D. James and J. S. Fossey, Chem. - Asian J., 2015, 10, 1836-1848.

45 X. Sun, Q. Xu, G. Kim, S. E. Flower, J. P. Lowe, J. Yoon, J. S. Fossey, X. Qian, S. D. Bull and T. D. James, Chem. Sci., 2014, 5, 3368-3373.

46 X. Sun, S.-Y. Xu, S. E. Flower, J. S. Fossey, X. Qian and T. D. James, Chem. Commun., 2013, 49, 8311-8313.

47 X. Sun, K. Lacina, E. C. Ramsamy, S. E. Flower, J. S. Fossey, X. Qian, E. V. Anslyn, S. D. Bull and T. D. James, Chem. Sci., 2015, 6, 2963-2967.

48 T. D. James, K. R. A. S. Sandanayake and S. Shinkai, J. Chem. Soc., Chem. Commun., 1994, 477-478.

49 T. D. James, K. R. A. S. Sandanayake, R. Iguchi and S. Shinkai, J. Am Chem. Soc., 1995, 117, 8982-8987.

50 T. D. James, P. Linnane and S. Shinkai, Chem. Commun., 1996, 281-288.

51 A. Stephenson-Brown, A. L. Acton, J. A. Preece, J. S. Fossey and P. M. Mendes, Chem. Sci., 2015, 6, 5114-5119.

52 X. Sun, B. Zhu, D.-K. Ji, Q. Chen, X.-P. He, G.-R. Chen and T. D. James, ACS Appl. Mater. Interfaces, 2014, 6, 10078-10082.

53 A. Stephenson-Brown, S. Yong, M. H. Mansor, Z. Hussein, N.-C. Yip, P. M. Mendes, J. S. Fossey and F. J. Rawson, Chem. Commun., 2015, 51, 17213-17216.

54 Y. Liu, C. Deng, L. Tang, A. Qin, R. Hu, J. Z. Sun and B. Z. Tang, J. Am. Chem. Soc., 2011, 133, 660-663.

55 Y. J. Heo and S. Takeuchi, Adv. Healthcare Mater., 2013, 2, 43-56.

56 T. D. James, K. R. A. S. Sandanayake and S. Shinkai, Angew. Chem., Int. Ed. Engl., 1996, 35, 1910-1922.

57 W. Yang, S. Gao, X. Gao, V. V. R. Karnati, W. Ni, B. Wang, W. B. Hooks, J. Carson and B. Weston, Bioorg. Med. Chem. Lett., 2002, 12, 2175-2177.

58 W. Yang, H. Fan, X. Gao, S. Gao, V. V. R. Karnati, W. Ni, W. B. Hooks, J. Carson, B. Weston and B. Wang, Chem. Biol., 2004, 11, 439-448.

59 S. Craig, Bioorg. Chem., 2012, 40, 137-142.

60 C. Dai, L. H. Cazares, L. Wang, Y. Chu, S. L. Wang, D. A. Troyer, O. J. Semmes, R. R. Drake and B. Wang, Chem. Commun., 2011, 47, 10338-10340.

61 Y. Chu, D. Z. Wang, K. Wang, Z. R. Liu, B. Weston and B. H. Wang, Bioorg. Med. Chem. Lett., 2013, 23, 6307-6309.

$62 \mathrm{X} . \mathrm{D} . \mathrm{Xu}, \mathrm{H}$. Cheng, W. H. Chen, S. X. Cheng, R. X. Zhuo and X. Z. Zhang, Sci. Rep., 2013, 3, 2679.

63 Confocal laser scanning microscopy (CLSM) is a technique for obtaining high-resolution optical images with depth selectivity.

64 T. L. Halo, J. Appelbaum, E. M. Hobert, D. M. Balkin and A. Schepartz, J. Am. Chem. Soc., 2009, 131, 438-439.
65 K. K. Kim, J. O. Escobedo, N. N. St. Luce, O. Rusin, D. Wong and R. M. Strongin, Org. Lett., 2003, 5, 5007-5010.

66 P. M. S. D. Cal, R. F. M. Frade, V. Chudasama, C. Cordeiro, S. Caddick and P. M. P. Gois, Chem. Commun., 2014, 50, 5261-5263.

67 C.-S. Chen, X.-D. Xu, Y. Wang, J. Yang, H.-Z. Jia, H. Cheng, C.-C. Chu, R.-X. Zhuo and X.-Z. Zhang, Small, 2013, 9, 920-926.

68 J. N. Cambre and B. S. Sumerlin, Polymer, 2011, 52, 4631-4643.

69 W. L. A. Brooks and B. S. Sumerlin, Chem. Rev., 2015, DOI: 10.1021/ acs.chemrev.5b00300.

70 M. C. Roberts, M. C. Hanson, A. P. Massey, E. A. Karren and P. F. Kiser, Adv. Mater., 2007, 19, 2503-2507.

71 J. I. Jay, S. Shukair, K. Langheinrich, M. C. Hanson, G. C. Cianci, T. J. Johnson, M. R. Clark, T. J. Hope and P. F. Kiser, Adv. Funct. Mater., 2009, 19, 2969-2977.

72 C. W. Garner, J. Biol. Chem., 1980, 255, 5064-5068.

73 D. A. Matthews, R. A. Alden, J. J. Birktoft, S. T. Freer and J. Kraut, J. Biol. Chem., 1975, 250, 7120-7126.

74 G. Kahraman, O. Beşkardeş, Z. M. O. Rzaev and E. Pişkin, Polymer, 2004, 45, 5813-5828.

75 L. Zhang, Y. Lin, J. Wang, W. Yao, W. Wu and X. Jiang, Macromol. Rapid Commun., 2011, 32, 534-539.

76 Y. Hu, X. Jiang, L. Zhang, J. Fan and W. Wu, Biosens. Bioelectron., 2013, 48, 94-99.

77 K. Lacina, P. Skladal and T. James, Chem. Cent. J., 2014, 8, 60.

78 Y. Zhao, B. G. Trewyn, I. I. Slowing and V. S.-Y. Lin, J. Am. Chem. Soc., 2009, 131, 8398-8400.

79 W. Wu, T. Zhou, A. Berliner, P. Banerjee and S. Zhou, Angew. Chem., Int. Ed. Engl., 2010, 49, 6554-6558.

80 H. Shibata, Y. J. Heo, T. Okitsu, Y. Matsunaga, T. Kawanishi and S. Takeuchi, Proc. Natl. Acad. Sci. U. S. A., 2010, 107, 17894-17898.

81 Y. J. Heo, H. Shibata, T. Okitsu, T. Kawanishi and S. Takeuchi, Proc. Natl. Acad. Sci. U. S. A., 2011, 108, 13399-13403.

82 M. P. Pereira Morais, D. Marshall, S. E. Flower, C. J. Caunt, T. D. James, R. J. Williams, N. R. Waterfield and J. M. van den Elsen, Sci. Rep., 2013, 3, 1431-1437.

83 G. Wulff, Pure Appl. Chem., 1982, 54, 2093-2102.

84 M. Dowlut and D. G. Hall, J. Am. Chem. Soc., 2006, 128, 4226-4227.

85 M. S. Shim and Y. J. Kwon, FEBS J., 2010, 277, 4814-4827.

86 S. Patil, D. Rhodes and D. Burgess, AAPS J., 2005, 7, E61-E77.

87 G. A. Ellis, M. J. Palte and R. T. Raines, J. Am. Chem. Soc., 2012, 134, 3631-3634.

88 H. Kim, Y. J. Kang, S. Kang and K. T. Kim, J. Am. Chem. Soc., 2012, 134, 4030-4033.

89 K. Nienhaus and G. Ulrich Nienhaus, Chem. Soc. Rev., 2014, 43, 1088-1106.

90 http://www.alzheimers.org.uk/, accessed November 2015.

91 J. S. Fossey and W. D. G. Brittain, Org. Chem. Front., 2015, 2, 101-105. 